\title{
encontrar escola: o tempo livre como criação de outro modo de habitar a instituição
}

\author{
fabiana fernandes ribeiro martins ${ }^{1}$ \\ universidade do estado do rio de janeiro - brasil
}

\section{resumo}

No presente artigo visamos a colocar em questão a instituição escolar e a problematizar as recentes críticas que apontam para a ineficácia dessa instituição na atual conjuntura sociopolítica. Como instituição moderna, que foi criada tendo como função principal a formação de sujeitos para a ordem social, a escola institucionalizada se vê cindida por definições que lhe são exteriores: seus currículos e suas avaliações, seus discursos e suas práticas são definidas, de antemão, pela sociedade na qual se insere. A estreita vinculação entre escolarização e socialização estabelece, no espaço escolar, uma condição de desigualdade entre aqueles que ensinam e aqueles que aprendem. Essa desigualdade se sustenta, sobretudo, na supervalorização do conhecimento, o qual, entendido como verdadeiro, seria o instrumento que viabilizaria, findado o processo escolar, a igualdade dos escolares no meio social. Face à atual conjuntura do capitalismo financeiro, assiste-se o surgimento da linguagem do aprender (BIESTA, 2013a, 2013b, 2013c), paralelamente ao aumento de críticas que apontam para a ineficácia e ineficiência da escola. Nesse movimento, contudo, a escola - seu espaço, seu tempo e sua função - não é colocada em questão. A pergunta que norteia o presente artigo é, portanto, "o que faz da escola uma escola?". Partimos da experiência de pesquisa do curso "Sobre a escola (pública) e o ato educativo ou sobre a experiência de pesquisa como verificação da igualdade. Encontrar uma escola em/ para o Rio de Janeiro: andar e falar como práticas de pesquisa educativa", realizado em 2012, no Rio de Janeiro, para trabalhar a concepção de escola como tempo livre, em referência à etimologia da palavra grega skholé. Por fim, visamos a colocar em questão a supremacia do saber da instituição e a pensar a igualdade como condição de encontrar escola.

palavras-chave: instituição; tempo livre; conhecimento; igualdade.

\section{to find school: free time as creation of another way of inhabiting the institution}

abstract

In this article we aim to problematize schools as institutions in order to question current academic output on education that accuses schools of not fulfilling the purposes which legitimize their existence in sociopolitical situation. From a modern point of view which considers education as formation (or training) for social order, school has its parameters established by outside: its curriculum and evaluations, its discourses and practices are defined from social order to school. This close link between school and society, which is based on the presumption that school constitutes a time for formation, creates an unequal relationship between those who teach and those who are supposed to learn. This inequality is, on one hand, caused by the relevance attributed to knowledge in the acting of learning and, in the other hand, by the belief that schooling is an indispensable process for insertion into the social sphere where equal would be achieved. Given the current role that financial capitalism plays into society, it is seen the emergence of the language of learning (BIESTA, 2013a, 2013b, 2013c) in parallel with the increase of criticism that points to the ineffectiveness and inefficiency of schooling. In presuming that school - through its

\footnotetext{
${ }^{1}$ E-mail: fabitins@gmail.com
} 
architecture, organization and founding principles - is a given in society, much of current academic output on education is dedicated to the study of school's purposes, content and methods, distancing themselves from the problematic of school's very existence. Then, the question at the core of this paper is: "what makes school school?". Following this purpose, this paper presents an experience of research that has been taken in a course occurred in 2012, in the city of Rio de Janeiro, called "Regarding the (public) school and the 'educational act': the experience of inquiry and the verification of equality. Finding/Designing a public school (people's school/ école du peuple) in/for Rio. Walking and talking as educational research practices", in order to work on the concept of school as free time, according to the etymological origin of the Greek word skholé. Finally, it is put into question the place given to knowledge in the institution and it is suggested to think equality as a condition to find school.

keywords: institution; free time; knowledge; equality.

\section{encontrar escuela: el tiempo libre como creación de otro modo de habitar la institución}

resumen

En el presente artículo tenemos el objetivo de cuestionar la institución escolar y problematizar las recientes críticas que apuntan para la ineficacia de esa institución en la actual coyuntura sociopolítica. Como institución moderna, que fue creada teniendo como función principal la formación de sujetos para el orden social, la escuela institucionalizada se ve dividida por definiciones que le son externas: sus currículos y evaluaciones, sus discursos y sus prácticas son definidas, de antemano, por la sociedad en la cual se insiere. La estrecha vinculación entre escolarización y socialización establece, en el espacio escolar, una condición de desigualdad entre aquellos que enseñan y aquellos que aprenden. Esa desigualdad se sustenta, sobre todo, en la sobrevalorización del conocimiento, el cual entendido como verdadero, sería el instrumento que viabiliza, después del proceso escolar, la igualdad de los escolares en el medio social. De cara a la actual coyuntura del capitalismo financiero, se asiste al surgimiento del lenguaje del aprender, (BIESTA, 2013a, 2013b, 2013c), paralelamente al aumento de críticas que apuntan para la ineficacia y ineficiencia de la escuela. En este movimiento, con todo, la escuela -su espacio, su tiempo y su función- no es colocada en cuestión. La pregunta que nortea el presente artículo es, por tanto, “QQué hace de la escuela una escuela?" Partimos de la experiencia de investigación del curso "Sobre la escuela (pública) y el acto educativo o sobre la experiencia de investigación como verificación de igualdad. Encontrar escuela en/para Río de Janeiro: caminar y hablar como prácticas de investigación educativa", realizado en 2012, en Río de Janeiro, para trabajar la concepción de escuela como tiempo libre, en referencia a la etimología de la palabra griega skholé. Por último, nuestro objetivo es poner en tela de juicio la supremacía del conocimiento de la institución y pensar en la igualdad como condición para encontrar escuela.

palabras clave: institución; tiempo libre; conocimiento; igualdad. 
encontrar escola: o tempo livre como criação de outro modo de habitar a instituição

Não raro, a instituição escolar tem sido acusada de não estar realizando o projeto social que lhe foi designado. Fala-se sobre a crise da escola e o desmantelamento da imagem social da instituição, o que tem levado ao surgimento de produções acadêmicas que visariam a restabelecer a relação entre escola e sociedade (RANCIÈRE, 1998; 2003). Se, por um lado, assistimos a emergência de discursos que concebem a educação como uma questão pessoal ou uma escolha instrumental, por outro lado vemos surgir discursos que entendem a educação como um processo privilegiado para a construção de uma sociedade ideal, democrática, solidária, inclusiva, justa e pacífica (BIESTA; SÄFSTRÖM, 2011a).

Sob o primeiro ponto de vista, eminentemente funcional, o professor seria um agente facilitador de aprendizagens e teria como função principal trabalhar com os conhecimentos a fim de atender às demandas dos alunos, sendo notória a utilização de termos concernentes à ordem social, sobretudo aqueles emprestados da economia, tais como capital humano e empreendedorismo. Nesse sentido, a escola se configuraria como um tempo destinado às demandas individuais dos alunos, as quais seriam, sobretudo, sociais - de aquisição de habilidades e competências -, para a futura vida no mercado de trabalho, no bojo da cultura do empreendedorismo que prioriza o ponto de vista da relação custo versus benefício. A escola é, aí, um espaço de investimento para a vida futura no mercado de trabalho, um tempo de preparação para um fim exterior a ela.

Sob o segundo ponto de vista, que poderíamos chamar de idealista, a escola seria um espaço de conscientização e, como tal, lugar privilegiado para a construção de uma futura sociedade menos desigual. Neste sentido, a escolarização seria marcada por uma temporalidade privilegiada: no presente, trabalharia a fim de favorecer a construção de alicerces necessários para o futuro exercício da cidadania. Aí, o conhecimento não é visto como meio para a formação do trabalhador, mas como um instrumento capaz de interferir nas fraturas sociais e diminuir as desigualdades (BIESTA; SÄFSTRÖM, 2011a). 
Entre estes dois extremos, é possível encontrar produções acadêmicas que buscam articular tanto a primeira quanto a segunda visão, argumentando que a questão central da atualidade é rever a agenda para uma educação condizente com a realidade dos dias de hoje. $\mathrm{Ou}$, ainda, encontram-se trabalhos acadêmicos nos quais há uma ode ao desenvolvimento científico e tecnológico e a defesa de uma escola adaptada aos novos moldes de aprendizagem, notadamente aqueles cujas disciplinas seriam transformadas em módulos elegidos e selecionados pelos "aprendizes", onde o professores se tornaria um mediador - ou facilitador - de aprendizagens (BIESTA; SÄFSTRÖM, 2011a; MASSCHELEIN; SIMONS, 2014).

Não obstante a comum acusação de que a escola teria se tornado um espaço obsoleto e muito distante da realidade dos alunos - incluindo aí seu currículo e suas práticas -, essas produções se assentam na afirmação de que é preciso readaptar a escola à atualidade. Escola e sociedade estão, aí, intrinsecamente relacionadas. Sob uma temporalidade tipológica sociocultural (FABIAN, 1983), a educação formal é concebida, então, apesar da divergência político-ideológica entre os pontos de vista acima mencionados, como um processo temporal linear e progressivo.

Ainda, em todos esses pontos de vista, trabalha-se sobre o pressuposto da existência da escola como uma necessidade social. Se, por um lado, o processo escolar é compreendido como um tempo destinado ao atendimento das necessidades individuais para inserção na sociedade, por outro lado, concebe-se um ideal escolar que se assenta na premissa de que a escola tem papel crucial na transformação da ordem social. De uma maneira ou outra, existem aí pressupostos que definem o que a escola é e visam estabelecer metas para que ela se torne o que ainda não é: ou bem a escola é vista como um espaço de formação para o mercado de trabalho, e, portanto, precisa rever seu currículo e suas práticas para lograr este objetivo, ou bem esta instituição é compreendida como um espaço no qual se formam sujeitos para uma transformação social, e precisa, então, rever seus pressupostos e suas metas.

Como instituição social, a escola, que trabalha com uma concepção progressista de tempo, se vê cindida por uma tipologia temporal sociocultural, 
que sustenta a impossibilidade de coexistências temporais. Para Fabian (1983), a concepção de evolução, presente na sociedade ocidental contemporânea, teria levado à "secularização do tempo", e "tempo" passa a ser o referencial inerente para se pensar o outro. Nesse sentido, passa-se a trabalhar com binarismos, tais como evoluído e não-evoluído, culto e não-culto, moderno e tradicional, rural e urbano, etc. - o que faz do tempo mais do que uma medida, uma qualidade de estados, entendendo diferença como distância temporal.

No interior do processo educativo institucionalizado, essa distância se mostra presente nos currículos, nas práticas e nos discursos: entre o sabido e o ainda não sabido, entre o formado e o ainda não formado, entre a série já cursada e os conhecimentos já adquiridos e a série ainda não cursada e os conhecimentos ainda não adquiridos. Para Biesta (2013b), essa forma de compreender o tempo, que transforma a diferença em distância - no bojo de uma economização do tempo, visivelmente presente nos currículos escolares, nas relações entre professores e alunos e nas prerrogativas e finalidades que sustentam os discursos a favor da instituição escolar - traz, a reboque, a supremacia do conhecimento no seio do processo educativo.

É nesse sentido que Rancière (2010) defende a tese segundo a qual a instituição escolar é, inevitavelmente, um lugar de embrutecimento. Pedra de toque da sociedade, o conhecimento é reelaborado na escola, no bojo do que se concebe por "transposição didática", em saberes disciplinares - processo de adaptação dos saberes socialmente legitimados que conforma os conhecimentos em currículos escolares ${ }^{2}$ - porque entende-se que é importante adquirir conhecimentos (processo comumente chamado de "aprender") e, sobretudo, que é preciso aprender de alguém que possui saberes e sabe como transmiti-los e explicá-los (nos termos da pedagogia, "alguém que sabe" é chamado de professor, cuja função principal é ensinar) ${ }^{3}$.

\footnotetext{
2 Tardif (2006) elabora o conceito de saberes curriculares a fim de categorizar o conhecimento escolar. Segundo o autor, esses saberes dizem respeito aos conteúdos definidos e selecionados como protótipos da cultura socialmente legitimada, aos objetivos que se visam alcançar através do processo de formação escolar e aos métodos usados para a transmissão de saberes.

${ }^{3}$ Ainda, segundo Tardif (2006, p.31, grifos nossos), o professor é, antes de tudo, "alguém que sabe alguma coisa e cuja função consiste em transmitir esse saber a outros". Isto é, no processo de desenvolvimento de seu trabalho, o professor elaboraria saberes experienciais, constituídos através
} 
$\mathrm{Na}$ instituição escolar, pois, ensino é o nome dado à transmissão de conhecimento de uma inteligência superior às inteligências inferiores, e aprender é o nome que se dá ao processo conduzido e direcionado por essa mesma inteligência, que visa a elevar as inteligências inferiores ao grau de superioridade. Àquele que aprende lhe é dito que só pode aprender porque tem alguém que lhe ensine: o processo de ensino e aprendizagem é, antes de tudo, a reafirmação da desigualdade das inteligências, a aferição de identidades, a concepção teleológica que entende diferença como distância (FABIAN, 1983).

Por isso, a explicação embrutece: conduz a regressão ao infinito, pela replicação das razões, e faz com que o aluno aceite sua condição de ignorante que precisa de um sábio, de uma inteligência superior, para lhe fazer aprender e compreender. O embrutecimento não é nada mais do que a marca de um método que "faz alguém falar para concluir que o que diz é inconsistente e que ele jamais o teria sabido, se alguém não lhe houvera indicado o caminho de demonstrar a si mesmo sua própria insignificância". Em outras palavras, "entende-se por embrutecedor o método que provoca no pensamento daquele que fala $o$ sentimento de sua própria incapacidade" (RANCIÈRE, 2003, p.188).

Todavia, se a modernidade havia feito da escola um espaço de formação de sujeitos para uma dada ordem social, a contemporaneidade radicaliza essa pressuposição e passa a pensar a escola sob uma perspectiva econômica. Aí, a aprendizagem se torna um conceito onipresente nos discursos educativos, entendendo que é ela, fundamentalmente, a mediadora dessa relação. Termos como "aprender a aprender", "aluno empreendedor de si", professor como mediador de aprendizagens se tornam, pois, comuns nos discursos contemporâneos, circunscritos numa linguagem do aprender (BIESTA, 2013a, 2013b, 2013c).

de suas práticas, e que articulariam os objetivos definidos pela instituição à realidade do cotidiano em sala de aula. Neste sentido, o saber docente seria um "saber plural", construído por saberes da formação profissional, que perfazem tanto conhecimentos científicos quanto formas de "saberfazer" (saberes disciplinares) oriundos de distintos campos do conhecimento (curriculares) e relativos aos discursos objetivos e métodos, a partir dos quais a instituição escolar constitui o modelo de formação (TARDIF, 2006). É notório o esforço de Tardif (e outros) em tentar equilibrar o conhecimento cientifico ao saber-fazer do cotidiano escolar, mas observa-se, ainda, um discurso alheio a duas questões importantes no presente artigo, quais sejam: a concepção de ensino como transmissão e a ideia de docência como lugar de saber. 
Nas escolas contemporâneas, afirma Deleuze (2013), verifica-se a instauração de formas de controle contínuas e a introdução da lógica empresarial dentro da escola. À escola, pois, lhe passa a ser impressa a tarefa de adequar-se às novas demandas de uma sociedade que vê na educação a formação de sujeitos empreendedores, flexíveis e adaptados, segundo a nova lógica do mercado de trabalho, cujos princípios meritocráticos tornam-se também princípios educativos e educadores (DELEUZE, 2003).

A questão que se coloca aqui, entre uma perspectiva e outra de educação, entre um modelo e outro de escola, é: o que faz a escola ser escola? Porque, se é verdade que a ela sempre se imprimiu finalidades em consonância com o meio social, resta-nos a indagação do que torna uma escola escola, para além da teleologia do processo educativo, para além da estreita e usual articulação entre escolarização e socialização (RANCIÈRE, 1988).

Retomando estudos dos filósofos gregos, Masschelein e Rancière encontram a concepção de escola como tempo livre, e sobre isso têm trabalhado em suas recentes pesquisas. Originalmente, a skholé, palavra grega que deu origem ao que hoje em português chamamos de "escola" era um tempo destinado ao estudo, cujo foco não era preparação para mercado de trabalho ou aquisição de conteúdos e habilidades. Primordialmente, o que a skholé realizava era uma separação dos jovens da ordem social e da família para o interior de um tempo onde todos eram iguais, independentemente da origem ou da classe. Em condição de igualdade, ali todos eram tornados escolares e tinham acesso aos mesmos estudos, livros e professores. O tempo, ali, não era teleológico, ou seja, não era destinado a uma finalidade, senão um tempo cuja marca era o próprio presente: estudava-se por estudar, pelo que o próprio estudo proporcionava de relação com a vida, consigo e com os outros.

No intuito de pensar as relações entre tempo e escola e recolocar a problemática a respeito da relação entre escola e sociedade, Jan Masschelein tem percorrido lugares do mundo com sucessivos grupos de estudantes da disciplina anual de Educação Social, ministrada por ele no curso de pós-graduação em Ciências da Educação, da Universidade de Louvain, Bélgica. Isto é, eles vão a 
alguma parte do mundo para explorar lugares, analisar usos e desusos de espaços, a fim de pensar o que é isso que, comumente, denominamos "escola". Essa experiência de pesquisa, intitulada "Encontrar escola", já percorreu diversas cidades do mundo, inclusive cidades marcadas por guerras e conflitos, como Saravejo, Belgrado e Tirana, bem como megalópoles pouco turísticas como Shenzhen e Chongqing, na China.

Nesse artigo, parte da vivência do curso realizado com Jan Masschelein no Rio de Janeiro, em 2012, é trazida no intuito de colocar em questão alguns conceitos e preceitos fortemente presentes no cotidiano escolar e no discurso educativo. Pouca coisa parece haver ficado entre a skholé e a instituição escolar, mas talvez dessa distância possamos encontrar alguma diferença e, dessa diferença, encontrar uma outra forma de habitar a escola que habitamos.

Ressalta-se, antes, que o presente texto não tem como foco a análise detalhada das metas e dos objetivos específicos do curso; tampouco visa a fazer um relato minucioso dos acontecimentos emergidos nos intensos dias em que o grupo de participantes do curso esteve caminhando pela cidade à procura de vestígios e parâmetros definidos, encontrando o inesperado ou se perdendo, muitas vezes, do esperado.

Se trazemos aqui a experiência do curso, não é por outro motivo que não pela potência que mostrou: por ter aberto tantas perguntas, feito balbuciar a língua, duvidar das certezas, hesitar frente ao habitual, estranhar o conhecido; não é pelo que o curso é ou propõe, mas pelo que ele fez pensar e, portanto, pôs a escrever. 


\section{per-cursos de uma experiência de pesquisa}

Em 2012, a convite da Universidade do Estado do Rio de Janeiro (UERJ), em parceria com a Universidade Federal Fluminense (UFF), Masschelein veio à cidade do Rio de Janeiro, e trouxe com ele os estudantes de pós-graduação em Ciências da Educação da Universidade de Louvain. Dessa vez, Masschelein esteve acompanhado também do arquiteto Win Cuyers, que vem desenvolvendo conjuntamente, há alguns anos, uma pesquisa que gira em torno das relações entre espaço, arquitetura e escola.

Jorge Larrosa, da Universidade de Barcelona, também esteve presente no curso, e trouxe sua contribuição de diversas maneiras. A partir do cinema realista de Pedro Costa - cineasta português cuja marca central do trabalho é produzir filmes sobre o singular, e que, portanto, não possui um método ou um modo único de fazer filmes (LARROSA, 2014) -, Larrosa fez intervenções em torno da ideia da pesquisa em educação como uma experiência de pesquisa, questionando, sobretudo, o papel da realidade e da verdade no processo da pesquisa.

Walter Kohan, professor anfitrião, deu suporte a este encontro, e esteve pensando o papel da igualdade na escola. Juntamente a ele, esteve Maximiliano López que, com base na antropologia que constituiria o "homem moderno", sustentou sua fala no sentido da crítica à maneira como a escola articula temporalidade, linguagem e alteridade.

Todos os cinco professores partilhavam leituras: tinham como referência suas próprias produções textuais, as quais dialogavam diretamente com os textos de Rancière e Agamben. Do ponto de vista teórico, então, o curso contou não só com o referencial bibliográfico dos próprios professores, mas também com a produção desses e de outros autores, entre os quais Vilém Flusser, Ivan Illich, Michel Foucault, que serviram de base para a construção da ementa.

Partilhar leituras, contudo, talvez não seja o suficiente para a construção de um curso, especialmente este, em que professores e estudantes de diferentes regiões e nacionalidades se predispuseram a estar juntos por duas intensas semanas, que intercalaram aulas expositivas com pesquisas de campo realizadas através de linhas de mapas da cidade - onde muitos estavam pela primeira vez. 
Havia algo comum que criava uma condição para que o curso acontecesse, algo comum que fazia com que emergissem dali possibilidades de encontros entre estrangeiros e anfitriões que não partilhavam uma língua comum; entre estudantes belgas e estudantes brasileiros que tinham relações institucionais distintas com o curso - para uns, o curso era parte de uma disciplina anual, para outros, uma atividade que tinha início, meio e fim naquelas duas semanas -; entre professores cujas leituras poderiam ser parecidas, mas as perspectivas eram distintas.

Em linhas gerais, o programa do curso apresentado no Rio foi dividido em dois momentos, que se intercalavam. Parte do curso foi destinada às aulas ministradas pelos professores, e outra parte foi destinada a percorrer a cidade do Rio de Janeiro, a pé, para "encontrar escola", ou, ainda, para pensar uma "escola para todos".

Na parte prática, o exercício não era complexo, ao contrário: os professores dividiam a turma em duplas, todas elas compostas por um estudante belga e um brasileiro, e entregavam partes do mapa da cidade do Rio de Janeiro para serem percorridas a pé, à procura de 16 parâmetros previamente pensados e definidos pelos professores. A cada parte desse percurso, os estudantes anotariam o que haviam observado em relação aos parâmetros. No final da jornada, cada dupla se dirigiria à universidade para reunião com os professores, para relatar o que havia observado, e, em seguida, teria um tempo destinado ao registro gráfico dos parâmetros encontrados, em um grande papel manteiga sobreposto a um mapa, reunindo informações georreferenciadas de todas as duplas, resultando em 16 grandes mapas temáticos da pesquisa na cidade, um para cada parâmetro.

Caminhar pela cidade, para encontrar algo, é caminhar atento e estabelecer com a cidade uma relação de autoridade, em que é ela que mostra os vestígios, que determina as veredas, os cruzamentos, as bifurcações, as ruas sem saída. Entre o que se deseja encontrar e o que se é mostrado, entre o que se procura e o que se acha, alguma coisa acontece que leva o caminhante a pensar - não porque a cidade impõe o que pensar, mas porque a cidade, com autoridade, tem autoria sobre o caminho por onde passam os passos daquele que percorre o mapa. No final de 
tantos dias de andanças, o curso teria como resultado 16 mapas da cidade, sob diversas perspectivas -, perspectivas, a princípio, questionadas pelos participantes, que discutiam o caráter (aparentemente?) aleatório dos parâmetros, tais como pontos de prostituição, cabines de polícia, prédios abandonados, comércio informal, pichações etc. Ademais, cada aluno deveria construir um projeto intitulado "escola para todos", a partir do que havia vivenciado na experiência de fazer a pesquisa pelas ruas do Rio de Janeiro.

\section{a pesquisa educativa como experiência de tempo livre}

Não havia uma rotina muito rígida, mas, de uma maneira geral, o curso se dividia entre a parte da manhã, destinada às aulas na Universidade, a parte da tarde, destinada à realização do percurso, e a parte da tarde-noite ficava reservada para a conversa entre alunos e professores a respeito das atividades do dia. Às vezes, o dia era destinado somente para a caminhada, mas, em todo caso, o que se propunha era que houvesse uma articulação direta entre teoria e prática, na assunção de que:

[...] a prática é um conjunto de revezamentos de um ponto teórico a outro, e a teoria um revezamento de uma prática a outra [...] teoria nenhuma pode se desenvolver sem encontrar uma espécie de muro, e é preciso a prática para atravessar o muro" (DELEUZE, 2010, p.265).

De maneira peculiar, ao formar duplas integrando nacionalidades diferentes, o curso foi tomando proporções distintas. O que esperar do encontro entre um estudante local e um estrangeiro? O que pode o caminho - a pé e por áreas desconhecidas numa cidade conhecida - provocar no pensamento? $\mathrm{O}$ que pode um estrangeiro, que sai de sua terra para fazer uma pesquisa educativa do outro lado do oceano, mover, provocar, incitar no hospitaleiro?

Foi preciso vencer a primeira barreira, a da língua: as duplas formadas na ocasião do curso não possuíam uma língua comum, muitas sequer tinham o inglês como mediação entre as partes. Foi preciso, pois, estar atento não somente à cidade, mas ao outro: este outro com o qual não se compartilhava a língua, mas com o qual se compartilhavam tantos passos e impressões, tantos medos, estranhamentos, encantamentos e dúvidas. Ademais, era preciso estar atento a si, 
também: a autoridade da cidade, em diversas situações, colocava o anfitrião, também, na condição de estrangeiro.

Ali, de todo modo, todos estavam em condição de igualdade: todos eram iguais não pela origem ou condição socioeconômica, senão pelo compartilhamento de um tempo livre das obrigações sociais, livre da produtividade, disponível para o estudo, para a pesquisa. A igualdade, então, diria respeito à condição de estudante: todos a que me refiro deixaram de lado suas vidas "produtivas" empregos, aulas, avaliações, relatórios, etc.- para se dedicar a "Encontrar Escola". Iguais porque, independentemente da vida fora daquele estudo, ali todos tinham acesso às mesmas aulas, aos mesmos filmes, aos mesmos professores; ali, a despeito das diferenças econômicas, sociais, políticas, etc., todos tinham a mesma tarefa a realizar, a mesma pesquisa a desenvolver.

Como no título do curso, "Sobre a escola (pública) e o ato educativo ou sobre a experiência de pesquisa como verificação da igualdade. Encontrar uma escola em/para o Rio de Janeiro: andar e falar como práticas de pesquisa educativa", a igualdade ali era pensada como uma condição (RANCIÈRE, 2010), ou, ainda, conforme salienta Kohan (2014), como “orientadora da busca”. Porque sem essa condição de igualdade - de tempo, a despeito das urgências, necessidades e expectativas fora da escola -, a pesquisa como experiência, e não como verificação, talvez não pudesse acontecer.

Como afirma Larrosa (2014), aquela velha ideia de pesquisa como verificação de verdade era suspensa, porque uma pesquisa em educação deve, em primeiro lugar, ser uma pesquisa do pesquisador sobre si; em outras palavras, para uma pesquisa ser educativa ela deve transformar o sujeito, colocar em questão o próprio pesquisador. Em segundo lugar, a educação é o tema ou a problemática para a qual os esforços da pesquisa se dirigem, portanto a pesquisa se torna educativa na medida em que tem como foco central a educação. Por último, em terceiro lugar, essa experiência de pesquisa em educação diz respeito a tornar algo público, ou, em outras palavras, a "desprivatizar" aquilo que, de algum modo, foi privatizado por um discurso único compartilhado pelo senso comum. 
Como fazer, então, dessa pesquisa uma experiência de tempo livre?

Para Masschelein (2014), quatro seriam as características básicas da skholé. A primeira diz respeito à suspensão, ou seja, à possibilidade de suspender a relação com a ordem social, de forma que, no interior da skholé, o tempo não se destine à produção de bens de subsistência, ou à manutenção da ordem. Mais que isso, a skholé separa seus participantes da ordem naturalizada pela sociedade, dando-lhes tempo livre (do mundo produtivo onde o trabalho é sempre realizado tendo em vista um fim a ser alcançado, um produto a ser finalizado) para o estudo. Essa suspensão diz respeito, ainda, à temporalidade com a qual vivemos, cotidianamente, demarcando passado, presente e futuro: o tempo livre se furta a ser um tempo entre outro tempo; ao contrário, ele é todo presente, tempo de olhar o mundo como se fosse a primeira vez, afirma Masschelein.

Ao suspender sua relação com a sociedade, e ao profanar os saberes e conhecimentos, a escola torna o mundo - ou, pelo menos, parte dele - interessante, gerando interesse dos estudantes em relação ao mundo (MASSCHELEIN; SIMONS, 2013).

Contudo, tão somente suspender o tempo talvez não seja suficiente: é necessário, ainda, a dessacralização dos conhecimentos legitimados socialmente, ou seja, deslocá-los de suas origens, quase que numa profanação, para que eles possam perder seus relações causais, suas conexões habituais, para serem repensados, reconsiderados.

Há, aí, um gesto: o de "pôr as coisas sobre a mesa", para serem vistas como se fosse a primeira vez. É por isso que a atenção é também uma condição da escola como tempo livre. É preciso atenção não exatamente porque há algo importante no que a escola mostra ou no professor diz, mas porque há algo de novo e de mágico do mundo que se apresenta, que se faz presente e, quiçá, faça pensar.

Por fim, a escola-skholé diz respeito, também, ao que Masschelein chama de amor público: ela é "espaço-tempo onde se experimenta, de forma comum, compartilhada, um amor pelo mundo tal como ele é, pelas coisas do mundo, onde se ama em comum certa dimensão de 'estar no mundo'”' (KOHAN, 2014, p.19). 
A proposta de pesquisa educativa a ser vivenciada nesses dias de curso foi, portanto, uma proposta de experiência de tempo livre. Contudo, nem todos os participantes conseguiram acolher esta ideia, pelos motivos mais diversos: alguns não conseguiram estar presentes no presente - a vida fora da escola lhes impelia a estar, constantemente, entre o tempo livre e o tempo produtivo, entre a tarefa de estar aberto ao novo, e a tarefa de ter que lidar com o antigo -; outros se furtavam a caminhar por tanto tempo por trechos tão grandes como aqueles selecionados para as duplas percorrerem, atentamente, à procura dos parâmetros préestabelecidos. Com sentidos diversos, para brasileiros e para belgas, o curso se apresentava ora como um desafio, ora como uma proposta difícil de ser compreendida e, portanto, aceita. Não raro, Masschelein dizia aos participantes para não questionarem, para não criticarem: pedia para que, primeiramente, a proposta fosse acolhida e feita, antes de qualquer problematização.

Em certo sentido, o que Masschelein dizia era que era preciso vivenciar o presente, a despeito do futuro; caminhar pelas linhas do mapa, à procura de parâmetros, a despeito de saber ou não o que essa caminhada daria de retorno ao participante; vivenciar a pesquisa a despeito das vivências de pesquisas anteriores. Era preciso, pois, afirmar a experiência de uma pesquisa educativa que começa sem saber exatamente onde vai chegar: experiência essa que não possui verdades a serem encontradas, tampouco metodologias de verificação de uma suposta verdade a ser descoberta. Nada está encoberto, as coisas estão no mundo, e a skholé diz respeito a colocar as coisas do mundo à mostra, à mesa, no presente.

Ao chamar os estudantes para o presente, e afirmar a atenção como condição para a caminhada, Masschelein afirma o papel do professor como aquele que torna possível a criação do tempo livre e, portanto, a afirmação da igualdade na escola. Na contracorrente da lógica do embrutecimento, o que faz do professor, professor, não é seu arcabouço de conteúdo, tampouco sua didática, mas seu amor pelo mundo.

Nesta perspectiva, o lugar ocupado pelo professor não é o lugar do saber que supostamente lhe conferiria uma superioridade -, mas o lugar de pôr as coisas sobre a mesa, no intuito de tornar público o conhecimento e, portanto, de criar um 
tempo de igualdade, apartado de uma sociedade marcadamente desigual e excludente. Nesse sentido, Masschelein sustenta a autoridade - como autoria, gesto de singular de criação - como conceito imprescindível para pensar a docência. Na "maestria pedagógica" trata-se,

[...] em primeira instância, não tanto de adquirir uma base de conhecimentos, mas de alcançar um estado de atenção e transformação do eu. Aqui, o planejamento, a redação e a leitura também podem ser exercícios preparatórios, mas têm o objetivo de fazer concordar pensamentos e ações, e criar um estado de inspiração ou de encarnação da verdade. Aqui também é importante o conhecimento, mas esse conhecimento é algo que se encarna. Aqui, exercer o conhecimento não significa aplicá-lo, senão encarná-lo em certo domínio de si (MASSCHELEIN; SIMONS, 2008, p.141).

A caminhada desse "per-curso", realizada em parceria, essa caminhada tantas vezes cansativa, ofegante, e mesmo frustrante - até porque muitas vezes se caminhava em busca dos parâmetros, e não atento a eles -, era um dispositivo para "penetrar no mundo" (MASSCHELEIN, 2014). Em outras palavras, uma maneira de fazer mover o olhar e tornar os estudantes atentos ao mundo. Porque, como bem lembra Larrosa, "não é difícil fazermos coisas. O que é difícil é pormonos em estado de fazê-las" (NEVES apud LARROSA, 2014, p.24): para fazer uma pesquisa como experiência não basta uma metodologia, ou um referencial bibliográfico denso, é preciso que o pesquisador se coloque "em estado de", entendendo que toda pesquisa educativa é singular, porque modifica aquele a que realiza. Por isso é preciso, também, uma espécie dietética da alma (LARROSA, 2014). Afinal, a skholé não diz respeito à liberdade pura e irrestrita, mas a uma liberdade - das demandas exteriores à escola - para o estudo e o pensamento.

Os critérios de definição a priori dos parâmetros seriam, segundo essa concepção educativa defendida por Masschelein, portanto, algo secundário; importaria, antes, a heterotopia que geraria as condições para alguém tornar-se estudante: alguém exposto e aberto a algo que não sabe exatamente o quê e nem como, num lugar sem lugar, onde não sabe bem como habitar e, portanto, precisa estar atento, à espreita.

Do total de estudantes que iniciou o curso, uma percentagem pequena abandonou a experiência. Os motivos eram diversos, mas, sobretudo, vivenciar um per-curso desse tipo exigia uma entrega que nem todos podiam dar. Como 
habitar um lugar sem lugar? Como extrair do não-lugar uma força criativa para um projeto de "escola para todos"?

Uns argumentaram que o exercício era sem sentido, que caminhar por caminhar não levaria a pensar a escola; outros acharam a proposta interessante, mas a exigência física da caminhada era um impeditivo. Dentre aqueles que moravam na própria cidade, era notório o medo em relação a algumas áreas da cidade, notadamente violentas - parte dos cariocas, então, resistiu ao curso, mas grande parte aproveitou o momento para ver o Rio por outros ângulos.

Entre o grupo dos estudantes belgas, era perceptível a maneira diferenciada com a qual se engajavam no curso. Por um lado, eles tinham neste curso uma parte integrante de uma disciplina anual que seria ainda continuada quando voltassem para a Bélgica. Por outro lado, o fato de virem do outro lado com continente gerava uma expectativa distinta àquela dos moradores do país hospitaleiro: traziam certezas e questionamentos, enquanto eram atravessados pela cultura local, permeada de possibilidades, idiossincrasias, paradoxos.

A despeito das diferenças institucionais - que não são poucas, mas que também não são primordiais, porque não determinam como cada um se relaciona com o exercício, com a cidade, consigo e com os outros - a proposta trazida pelos professores não era pequena: “Encontrar escola” em tempos em que a própria escola parece já não fazer muito sentido; "Encontrar escola”, quando se sente um certo cansaço de, cotidianamente, resistir às demandas sociais de eficiência e eficácia do ensino para uma aprendizagem que garanta uma empregabilidade, talvez demande alguma coisa mais do que uma predisposição física ou pedagógica. Talvez exija alguma coisa que diga respeito a estar aberto para que algo aconteça (inclusive nada), sem saber de antemão o que é, nem como pode chegar (se é que pode chegar) - estar atento para ver algo, talvez, invisível, e se colocar em condição de pensar algo quiçá impensável.

Neste sentido, afirma Kohan (2014, p.20):

Foi também notória a riqueza de experiência de formação a partir da leitura de alguns trabalhos expostos e das escritas promovidas a partir do próprio curso. Mesmo que a inspiração esteja mais dirigida ao processo do que ao produto, mesmo que ela seja mais dirigida ao andar do que ao ponto de chegada, algumas sentenças apresentadas pelos estudantes, no último dia do curso, ilustram essas três dimensões da pesquisa 
educacional elencada neste trabalho: colocar a si mesmo em questão; trabalhar uma questão educacional; tornar algo público.

\section{traços de considerações finais: como fazer escola na escola?}

O que pode a skholé ajudar a pensar a escola institucionalizada? Como pode a busca por uma "escola para todos" ajudar a superar o cansaço da instituição? Que mundos um percurso feito a pé, no traçado das fronteiras espaciais da cidade do Rio de Janeiro, pode abrir para professores e alunos? O que a pesquisa como experiência pode provocar no pensamento e na prática pedagógica? Em que medida a transformação do pesquisador nessa pesquisa educativa leva à problematização do dado, do instaurado, do instituído?

Por ora, pode-se dizer que existem duas escolas: a institucionalizada, do tempo produtivo, que pressupõe a desigualdade como relação educativa, tendo o saber socialmente constituído como mediação entre escolarização e socialização; e a do tempo livre, que, ao contrário, desloca o conhecimento da ordem social na qual foi construído, para colocá-lo à disposição dos estudantes, para que possa ser visto como se fosse a primeira vez.

A experiência escolar possibilitada pela skholé se dá no confronto entre o uso comum do conhecimento e a profanação desse conhecimento disposto aos estudantes, para uso distinto do habitual. Por isso, a escola como tempo livre trabalha com os saberes a partir do ponto de vista da criação, e não da transferência: importa menos a aquisição de conhecimentos do que o movimento do pensamento que conduz à criação de livres formas de uso ou à criação do novo. O que não quer dizer, contudo, que a escola como tempo livre seja espaço isolado da sociedade, mas sim que este espaço é mudado, pelo menos temporalmente, pelo ato de suspensão e profanação. Ou seja,

Escola/skholé, então, não deve ser confundida com a instituição [...]. Na verdade, a escola como instituição poderia ser considerada em muitos aspectos como uma forma de apropriar-se da escola/skholé, de destiná-la. De forma mais geral, poderíamos ler a história da escola como sistema/instituição/organização (e, provavelmente, também a história da filosofia da educação que a apoiou) talvez num sentido mais amplo como uma história de apropriação ou de domesticação de "tempo livre" (MASSCHELEIN, 2011, p.530-531). 
A educação, segundo esta perspectiva, não é sobre a representação do mundo, mas sobre a presentificação do mundo, pois:

O presente não é o que aparece, como tal e diante de nós (como um objeto de conhecimento), mas o que é experienciado quando nós estamos atentos ou quando estamos 'presentes no presente'. A evidência, assim, não é o que é simplesmente dado, mas o que aparece quando o olhar se preocupa com o presente. Presença não é uma simples visão: ela se oferece em encontros, receios ou preocupações. (MASSCHELEIN; SIMONS, 2013, p.171)

Contudo, estamos acostumados a fazer alguma coisa em razão de um fim: pautamos nossas vidas numa mensuração constante entre os esforços dos meios e os retornos dos fins, numa capitalização da vida que nos faz estar, a todo momento, pensando se "vale a pena", se "compensa". Na escola institucionalizada, não é diferente: antes de começar, os professores já sabem aonde vão chegar; inversamente, os alunos já têm, de antemão, a "receita" para aprender. Aí, então, a relação educativa, eminentemente teleológica, se sustenta sobre uma premissa de desigualdade, na qual os professores sabem e os alunos não sabem; os professores ensinam e os alunos aprendem; os professores, detentores de uma inteligência superior, transmitem metodologicamente conhecimentos a seus alunos, portadores de inteligência inferior, para que estes possam aprender o que devem aprender - e, ainda, da maneira como devem aprender (RANCIÈRE, 2010).

Se a instituição nos faz prestar elogio à verdade e à desigualdade, a skholé faz o convite para partir da condição da igualdade, suspender a relação com a sociedade, profanar a verdade sacralizada para, por fim, estar em condição de atenção com o mundo. E, dessa condição, criar uma maneira singular de se relacionar com o mundo, para além das identidades predefinidas social e culturalmente. Sob esta perspectiva, o professor não é o detentor do saber, e nem mesmo o saber é a pedra de toque da relação educativa, porque importa menos o saber do que a relação estabelecida com o saber.

Agora, uma cena me vem à cabeça, para continuar pensando modos de habitar a escola. Eu era recém-chegada na escola, que estava passando por um período de transição de professores. A escola, que contava com um projeto de bidocência, precisava que eu estivesse compondo a bidocência em duas turmas, 
tarefa não muito fácil para uma jovem professora... Com ajuda dos colegas e das crianças, fui criando maneiras de me adaptar na escola. Precisaríamos conversar com as crianças para que elas pudessem entender essa nova dinâmica. Uma turma foi enfática: não aceitaria me dividir com outra turma.

"Bom", disse eu, "a outra turma disse a mesma coisa, o que faremos, então? Precisamos pensar em uma saída". "Deixa eles para lá!", afirmaram. “Mas, e se eles derem a mesma ideia?”. “Ah, mas você está complicando as coisas...". "Eu não, eu estou querendo resolver... E preciso da ajuda de vocês", disse eu. "Já sei, a gente pega uma varinha mágica, faz 'sinsalabim' e pronto, transforma você em duas e tá resolvido!”, prontamente resolveu uma criança. “Ah, ótima ideia! Onde temos varinha mágica aqui?", perguntei, obviamente a novata da escola, porque logo contestou uma menina, meio sem paciência, gesticulando com as mãos: “a gente não tem varinha mágica, professora! Varinha mágica não existe!!! Essa ideia não vai dar certo".

Um pouco envergonhada, respondi dizendo que eu era somente uma adulta e que não sabia tudo. Aliás, fiz questão de salientar que, por ser professora nova na escola, eu ainda ia fazer muitas perguntas. Logo, então, outra criança (muito solidária, diga-se de passagem), resolve me ajudar, levanta a mão e, empolgada, diz: “já sei! Está resolvido: a gente faz um desenho bem grande seu e deixa lá, você fica aqui, e eles não vão nem perceber!”. “Ótimo”, disse eu, "mas, se eles falarem comigo, o desenho tem como responder?". “Isso não é o problema, a gente grava um gravador com a sua voz, e aí sempre que eles quiserem falar com você, eles apertam "play'", disse um menino que estava quieto prestando muita atenção.

Essa conversa foi longa... Bastante longa... Porque, de fato, a ideia foi ficando muito incrementada, com os problemas que fomos enfrentando: como o gravador iria responder às perguntas, se as respostas já estariam gravadas antes? Como o gravador saberia a pergunta que viria primeiro e a pergunta que viria depois? Como o gravador saberia responder a pergunta "esperta" e a pergunta "boba"? Existe pergunta "esperta" e pergunta "boba"? 
E fomos inventando modos para que eu pudesse habitar duas salas, duas turmas, duas (i)realidades... A cada dia, vamos inventando novas formas...

Às vezes, quando estou na outra sala, eles me visitam e me perguntam "qual a atividade dirigida que você vai fazer com a gente hoje?" ou "você vai fazer pintura com a gente também?". E a cada vez é preciso conversar... e fazer perceber... e sentir que cada turma é um mundo, e cada mundo tem seu modo de ser habitado, criado e reinventado, dependendo também de cada momento.

Se a instituição nos atribui papéis sociais específicos, impondo deveres e responsabilidades, estabelecendo critérios de diferenciação e distância, talvez a skholé nos ajude a resistir a essa lógica do embrutecimento. Estamos, nós, preparados para ver o comum naquilo que já se tornou habitual? Estamos, nós, sensíveis ao mundo de modo a permitir que ele nos comunique, nos afete, nos faça pensar? Quanto de novo, no velho, somos capazes ainda de ver, sentir e viver?

"Encontrar escola" talvez seja o nome dado àquilo que procuramos, cotidianamente, inventar dentro da própria escola: encontrar o sentido escolar dentro da instituição. E talvez isso venha, muitas vezes, pelo convite dos estudantes, quando como uma borboleta adentra a sala, ou um passarinho começa a cantar ao longe e nos convida a dançar.

\section{referências}

BIESTA, Gert. Para além da aprendizagem: educação democrática para um futuro humano. Tradução de Risaura Eichenberg. Belo Horizonte: Autêntica, 2013a. 206 p.

BIESTA, Gert. Time out: can education do and be done without time? In: SZKUDLAREK, Tomasz (ed.). Education and the political: new theoretical articulations. Rotterdam: Sense; 2013b. p.75-88

BIESTA, Gert. The beautiful risk of education. Boulder, Co: Paradigm; 2013c. 155 p. BIESTA, Gert. SÄFSTRÖM, Carl Anders. A manifesto for education. Policy futures in education [periódico na internet]. 2011 a 9 (5): 8 p. Disponível em:

<www.wwwords.co.uk/PFIE>Acesso em: 23 de novembro de 2013

DELEUZE, Gilles; FOUCAULT, Michel. Os intelectuais e o poder. Tradução de Hélio Rebello Cardoso Junior. In: LAPOUJADE, David (org.). A ilha deserta e outros textos: textos e entrevistas (1953-1974). São Paulo: Iluminuras, 2010. p.265-273

FABIAN, Johannes. Time and the other: how anthropology makes its object. New York: Columbia University Press, 1983. 197 p.

KOHAN, Walter. Um exercício que faz escola: nota para pensar a investigação educacional a partir de uma experiência de formação no Rio de Janeiro. In: MARTINS, Fabiana; NETTO, Maria; KOHAN, Walter (org). Encontrar escola: o ato educativo e a experiência da pesquisa em educação. Rio de Janeiro: Lamparina, FAPERJ, 2014. 
LARROSA, Jorge. Como entrar no quarto de Vanda: notas sobre a investigação como experiência (tendo como referência três filmes e alguns textos de Pedro Costa) e considerações sobre a investigação como verificação da igualdade (tendo como referência alguns textos de Jacques Rancière). In: MARTINS, Fabiana; NETTO, Maria; KOHAN, Walter (org). Encontrar escola: o ato educativo e a experiência da pesquisa em educação. Rio de Janeiro: Lamparina, FAPERJ, 2014.

MASSCHELEIN, Jan .Experimentum scholae: the world once more... but not (yet) finished. Stud Philos Educ. Oxford, 30. 2011.p. 529-535

MASSCHELEIN, Jan. O mundo "mais uma vez": andando sobre linhas. In: MARTINS, Fabiana; NETTO, Maria; KOHAN, Walter (org). Encontrar escola: 0 ato educativo e a experiência da pesquisa em educação. Rio de Janeiro: Lamparina, FAPERJ, 2014.

MASSCHELEIN, Jan; SIMONS, Maarten. Em defesa da escola: uma questão pública. Tradução de Cristina Antunes. Belo Horizonte: Autêntica, 2013, 174 p.

RANCIÈRE, Jacques. École, production, égalité. In: RENOU, Xavier (org). L'école de la démocratie. Paris, Edilig/Fondation Diderot, 1988. p. 2-13. Disponível em: <http://horlieueditions.com/textes-en-ligne/politique/ranciere-ecole-production-egalite.pdf $>$ Acesso em: 5 de dezembro de 2013

RANCIÈRE, Jacques. Atualidade de o mestre ignorante. Tradução de Lílian do Valle. Educ. Soc., Campinas, vol. 24, n. 82. p. 185-202, abril 2003 Disponível em:

<http:/ / www.cedes.unicamp.br>Acesso em: 10 de novembro 2013

RANCIÈRE, Jacques. O mestre ignorante: cinco lições sobre a emancipação intelectual. 3. ed. Tradução de Lílian do Valle. Belo Horizonte: Autêntica, 2010. 191 p.

TARDIF, Maurice. Saberes docentes e formação profissional. Petrópolis: Vozes, 2002.

recebido em: 26.12 .2016

aceito em: 28.02.2017 